University of Wollongong

Research Online

SMART Infrastructure Facility - Papers

Faculty of Engineering and Information

Sciences

$1-1-2016$

\title{
Individual-level simulation model for cost benefit analysis in healthcare
}

\author{
Nagesh Shukla \\ University of Wollongong, nshukla@uow.edu.au \\ Vu Lam Cao \\ University of Wollongong, vlcao@uow.edu.au \\ Van Hoang Phuong \\ University of New South Wales, v.hoang@unsw.edu.au \\ Marian D. Shanahan \\ University of New South Wales, m.shanahan@unsw.edu.au \\ Alison Ritter \\ University of New South Wales, a.ritter@unsw.edu.au
}

See next page for additional authors

Follow this and additional works at: https://ro.uow.edu.au/smartpapers

Part of the Engineering Commons, and the Physical Sciences and Mathematics Commons

Research Online is the open access institutional repository for the University of Wollongong. For further information contact the UOW Library: research-pubs@uow.edu.au 


\title{
Individual-level simulation model for cost benefit analysis in healthcare
}

\begin{abstract}
Illicit drug use creates significant burden at societal, family and personal levels. Every year substantial resources are allocated for treatment and the consequences of illicit drug use in Australia and around the world. Heroin is one of the major forms of illicit drugs. Several independent heroin treatment strategies or interventions exist and state-of-the art research demonstrates their efficacy and relative costeffectiveness. However, assessing total potential gains and burden from providing all treatment interventions or varying the mix of heroin treatments has never been attempted. This paper proposed an individual-level simulation model (ISM) which addresses net social benefit over a lifetime that can accommodate the complexity of individuals going in and out of multiple treatments and their corresponding costs and benefits arising from different treatments during the life-course of heroin users in the context of New South Wales (NSW) Australia. This model is intended to serve as an effective tool for economic evaluation and policy making in the illicit drug area in Australia. The validity of the model has been assessed by comparing short term outcomes or examining the status of participants at a various points of time predicted from the model with other data sets that were not used to parameterise the model. Initial model results have been also presented to highlight different types of scenario analysis that can be conducted in future.
\end{abstract}

\section{Keywords}

individual, level, healthcare, simulation, analysis, model, cost, benefit

Disciplines

Engineering | Physical Sciences and Mathematics

\section{Publication Details}

Shukla, N., Cao, V., Phuong, V., Shanahan, M., Ritter, A. \& Perez, P. (2016). Individual-level simulation model for cost benefit analysis in healthcare. In T. Claus, F. Hermann \& M. Manitz (Eds.), Proceedings, 30th European Conference on Modelling and Simulation, ECMS 2016 (pp. 138-144). United States: Springer.

\section{Authors}

Nagesh Shukla, Vu Lam Cao, Van Hoang Phuong, Marian D. Shanahan, Alison Ritter, and Pascal Perez 


\title{
Individual-level Simulation Model for cost benefit analysis in healthcare
}

\author{
Nagesh Shukla ${ }^{1 *}$, Vu Lam Cao ${ }^{1}$, Van Hoang Phuong ${ }^{2}$, Marian Shanahan ${ }^{2}$, Allison Ritter ${ }^{2}$, Pascal Perez ${ }^{1}$ \\ ${ }^{1}$ SMART Infrastructure Facility \\ Faculty of Engineering and Information Sciences \\ University of Wollongong \\ NSW, Australia 2522 \\ *Email: nshukla@uow.edu.au \\ ${ }^{2}$ Drug Policy Modelling Program \\ National Drug and Alcohol Research Centre \\ University of New South Wales \\ NSW, Australia 2052
}

\section{KEYWORDS}

Individual-level simulation model; Health Economics; Illicit Drug Use.

\begin{abstract}
Illicit drug use creates significant burden at societal, family and personal levels. Every year substantial resources are allocated for treatment and the consequences of illicit drug use in Australia and around the world. Heroin is one of the major forms of illicit drugs. Several independent heroin treatment strategies or interventions exist and state-of-theart research demonstrates their efficacy and relative costeffectiveness. However, assessing total potential gains and burden from providing all treatment interventions or varying the mix of heroin treatments has never been attempted. This paper proposed an individual-level simulation model (ISM) which addresses net social benefit over a lifetime that can accommodate the complexity of individuals going in and out of multiple treatments and their corresponding costs and benefits arising from different treatments during the life-course of heroin users in the context of New South Wales (NSW) Australia. This model is intended to serve as an effective tool for economic evaluation and policy making in the illicit drug area in Australia. The validity of the model has been assessed by comparing short term outcomes or examining the status of participants at a various points of time predicted from the model with other data sets that were not used to parameterise the model. Initial model results have been also presented to highlight different types of scenario analysis that can be conducted in future.
\end{abstract}

\section{INTRODUCTION}

This paper deals with the development of novel individuallevel simulation model (ISM) for health care decision making. The model is developed for modelling range of treatments available for illicit drug users. The model is simulated for long term (generally lifetime of drug users) to evaluate treatment services. Following paragraphs deal with the area of illicit drug use. Governments, non-governmental organizations (NGOs) and International Organizations worldwide invest hundreds of billions of dollars in health care projects. Australia spends around $10 \%$ of its GDP or AUD 100 billion per year in recent years in health care WDI (2012). In the area of illicit drug spending, Australian federal and state governments spend about AUD 1.7 billion per annum in prevention, treatment, harm reduction and law enforcement to combat illicit drugs. There is an increasing pressure from both the government and the public to know whether the current spending is optimal or what needs to change to increase the benefits of spending. This is particularly important for complicated policies where there are many external costs and benefits, and as such; there are diverse views about the value of the interventions.

Existing research demonstrates efficacy and relative costeffectiveness for individual heroin treatments, such as pharmacotherapy maintenance. "Cost of illness" studies have estimated the total social burden related to all illicit drugs, and have been important in communicating this burden. But these studies do not provide evidence on the total potential gains from all interventions. And neither of these approaches can be used to value the net benefit, over the lifespan, of providing a system of heroin treatment interventions. There is a pressing need to demonstrate whether the existing combinations of heroin treatment interventions are a good investment for government. The aim of this paper is to develop a modelling approach which can assess the net social benefit of current heroin treatment strategies, and compare different combinations of treatment alternatives through modelled scenarios. This will lead to better informed policy decisions about the mix and type of treatments. The critical methodological issue is the choice of modelling approach. The model needs to capture recurring events over time as well as reflect alternative trajectories for individuals who use heroin. The chosen model is a micro-simulation model, also referred to as an ISM. It depicts events and outcomes at the level of the individual. The ISM enables 'memory' for each individual of such things as the length of heroin use, past treatments and incarcerations. This paper describes the rationale for an ISM and provides the detailed methodology employed to develop the ISM of heroin careers.

\section{Literature ReVieW}

The decision problem of heroin use with recurring events such as abstinence, crime, incarceration, and treatment over time can be modelled using state transition models (STM). STMs consist of set of mutually exclusive and collectively exhaustive health states. Individuals can transition among 
these health states based on prescribed transition probabilities. Interactions between individuals are ignored in STMs. One of the predominantly used STM in substance abuse literature is cohort-based STM also know as Markov model (Schackman et al. (2011)). Cohort-based STMs are relatively simpler to develop when the number of health states is not large. These models are restricted by the Markovian assumption, where transition probabilities do not depend on individual history or memory (i.e. past health states or state duration) Siebert et al. (2012). In case of heroin use, it is recognised that individuals history of incarceration, treatment, and length of time in treatment has an effect on state transition of an individual (Hser et al. (2004), Zhang et al. (2003)). Therefore, it is necessary to include the information about individual history while modelling heroin users based on STM. Cohort-based model can handle memory by having additional health states to include history, however, it often results in a very large model which is difficult to handle. On the other hand, individuallevel simulation model (ISM) or individual-level STMs are not restricted by the Markovian assumptions as they simulate individuals history by using tracker variables. This greatly reduces the number of health states required.

ISMs better represent heterogeneity among individuals in complex modelling scenarios such as illicit drug use. ISMs can model individual characteristics as continuous variables whereby future decisions depend on current and past individual history. In case of cohort-based STMs, individual characteristics needs to be categorized to make separate health states Siebert et al. (2012). The ISMs can easily handle individual specific time steps as individuals in the model are simulated one at a time.

\section{MODEL OVERVIEW}

The ISM model in this paper starts with the population of individuals who have ever used heroin (previously and currently) for the New South Wales (NSW) state of Australia. These individuals are distributed in various health/treatment states (eg, abstinence, irregular use, dependent use, various treatment, prison and death states). Overall model working is conceptually represented in Fig. 1. There are six model components which are conceptually defined, namely, the initial population, health states, state transitions, costs and outcomes (these will be attached where relevant to being in a given state i.e. treatment, prison, societal costs of crime), and net social benefit.

The model starts with the initial population of current heroin users and heroin abstainers. This population of individuals are transitioned from one health state to other using predefined (individual based) state transition probabilities. After each state transition, outcomes such as heroin use, crime committed; and resource implications are computed. This process is repeated at each time step (where time step is defined as the length of stay in each state, individually driven) until the end of simulation time period is reached. Each year, a sub-population of new drug initiators is added to the current population to include new drug users, along with a mortality rate which exists for the model). Finally, net social benefit is computed based on the outcomes of the simulation model. Following section provides more detail on each of the model components.

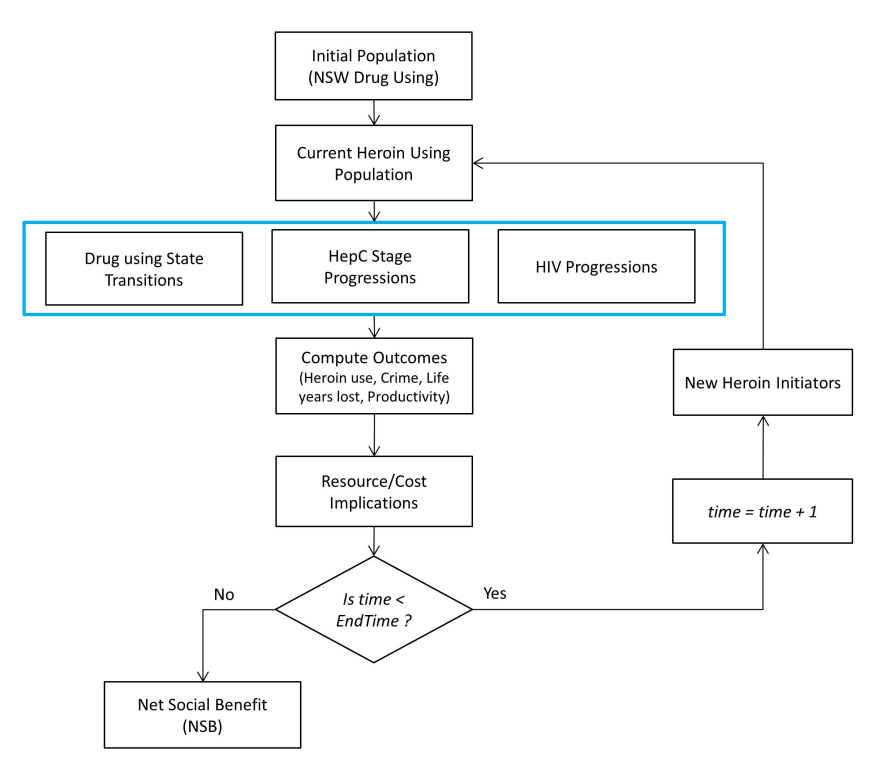

Fig. 1. Model Overview

\section{Initial Population}

The initial population in the current model was estimated based on the current NSW heroin using population. This includes those currently abstinent, those in treatment subgroups as well as those currently in heroin using subgroup. The characteristics of the initial population that were selected were age, gender, treatment history (number of episodes and duration of treatment), HIV and Hepatitis-C status; which were obtained from a number of data sources.

\section{States}

In the ISM, we have used three important locations (stages) in the drug using individuals trajectory : i) in community, ii) in prison, and iii) death.The first two stages are considered in this study to model the cost, benefit and treatment variations in drug using population. Exit from the model occurs if alive at age 60 , death from drug related or non-drug related causes. Hence the total number of states is provided in Table I.

TABLE I. TOTAL NUMBER OF HEALTH STATES BASED ON HEROIN USE AND STAGES

\begin{tabular}{|c|c|c|}
\hline State & Stage & Description \\
\hline Abstinence(S1) & COMMUNITY & not using \\
\hline Irregular use(S2) & COMMUNITY & use irregularly \\
\hline No Treatment \& Use(S3) & COMMUNITY & $\begin{array}{l}\text { dependent users } \\
\text { with no treatment }\end{array}$ \\
\hline Withdrawal(S4) & COMMUNITY & $\begin{array}{l}\text { Withdrawal } \\
\text { treatment }\end{array}$ \\
\hline Residential rehab.(S5) & COMMUNITY & rehabilitation \\
\hline Pharmacotherapy (S6) & COMMUNITY & $\begin{array}{l}\text { provision of } \\
\text { safe opioid }\end{array}$ \\
\hline Counselling Only(S7) & COMMUNITY & $\begin{array}{l}\text { psychological } \\
\text { therapy }\end{array}$ \\
\hline Prison No Treatment(S8) & PRISON & not in treatment \\
\hline Treatment in Prison(S9) & PRISON & in treatment \\
\hline Death or $60+$ years old & DEATH & $\begin{array}{l}\text { death from all } \\
\text { causes }\end{array}$ \\
\hline
\end{tabular}




\section{Transition Time}

In this model, an approach which provides heterogeneous time to transition for each individual is used. We have used length of stay (LOS) distributions for each individual. This is due to the fact that previous research has shown that LOS is highly predictive of subsequent drug use outcomes (Zhang et al. (2003), Hser et al. (2004)).

The distributions of LOS of an episode is created and assigned to each individual in the model. The LOS varies depending on individual characteristics (such as previous treatment episodes, age, gender, amount of drug use, state). The LOS based on individual characteristics were used only where sustained evidence exist (i.e. at least two empirical evidences to confirm). See Table II for data sources. Two type of survey dataset such as Alcohol and Other Drug Treatment Services National Minimum Data Set (AODTS-NMDS) and Australian Treatment Outcome Study (ATOS) have been used.

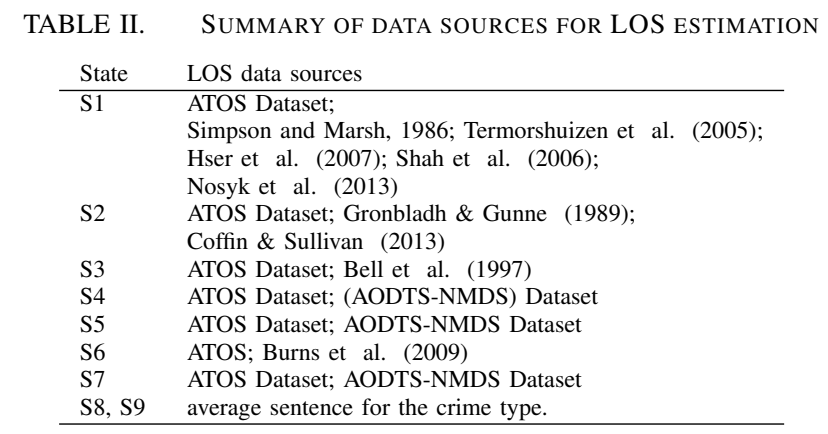

\section{State Transitions}

Once individuals in each state finish their assigned LOS in a state, they transition to other state based on transition probability functions. These functions are dependent upon the individuals attributes. In the model, these probabilities were estimated based on number of data sources. Australian treatment and outcome study (ATOS) dataset, MIX dataset, and relevant literature were used to estimate these probability functions.

\section{Costs and Outcomes}

The individuals in the model transition from one state to another and in this process costs and outcomes (also referred to as rewards) are accrued. The resources were attached to individual when they were in certain states and are referred to as state awards. For example, while in S4 (withdrawal in the community), the cost per day of withdrawal is attached; similarly cost was attached to residential rehabilitation (by days in RR); pharmacotherapy (by days in OTP); counselling (by days); prison (days); treatment in prison (days in OTP). Average unit costs by treatment type were applied.

The variation in resource use is driven by the length of time in a state. There are resources attached to some transitions (transition awards) i.e. transitioning into prison would incur the costs of the police and court. Total costs include the following components: (i) value of life-years (saved, or lost), (ii) treatment costs; (iii) other health care utilisation (i.e. treatment for specific diseases such as HIV, Hepatitis C), (iv) crime and criminal justice system costs. Total benefits include: earnings due to individuals returning to work after successful treatments.

\section{Net social benefit}

Once the costs and benefits have been calculated, the criterion for assessing the overall efficiency of an intervention is the Net Social Benefit (NSB) Feldstein (1964). The main costs and benefits will be calculated based on participants life time trajectories, during which they may be employed, use health care services, contract HIV or Hep C, commit crimes and go to prison. The base model will characterize the statusquo of behaviours of heroin users and calculate the base net social cost-benefit of current heroin treatment arrangement in NSW; different policy options can be explored to find the best combination of treatments that gives the highest net social costbenefit.

\section{DATA SOURCES FOR THE MODEL}

\section{Initial Population}

The initial population for the model provides an estimate for the number of individuals within each of the 9 states in the model. States S10 was not included in the initial population as this state relates to death. The figures for each state were derived from various recent data sources discussed in this section (where possible from years 2012-2013). The final numbers have been rounded, to reflect the lack of precision in the estimates (see Table III).

\begin{tabular}{|c|c|c|}
\hline \multirow[t]{12}{*}{ TABLE III. } & \multicolumn{2}{|c|}{ FINAL STARTING POPULATION NUMBERS } \\
\hline & State & Starting number \\
\hline & S1 & 22,000 \\
\hline & S2 & 53,000 \\
\hline & S3 & 16,500 \\
\hline & S4 & 20 \\
\hline & S5 & 80 \\
\hline & S6 & 17,500 \\
\hline & S7 & 100 \\
\hline & S8 & 1,100 \\
\hline & S9 & 1,100 \\
\hline & TOTAL & 111,400 \\
\hline
\end{tabular}

\section{Transition Functions}

The proposed model simulated life trajectories of heroin users in NSW based on the transition matrix, which lays out all possible transitions from one state to the other state over participants life time. The possible transitions are determined by the availability of treatment modalities in NSW and characteristics of heroin use such as initiation, developing to dependent use, participating in treatment, abstinence, relapsing and so on. A participant makes transition to one of mutually exclusive states once he/she has completed a LOS for the episode. Multiple datasets and published literature were used or combined to estimate the parameters for transition functions.

Transitions from community states to community states: ATOS was the primary dataset to estimate transition probability functions from community states to community states. In addition, evidence from literature was used together with ATOS estimates to determine the final transition probabilities. 
Transitions from community states to prison states: Participants in $\mathrm{S} 1, \mathrm{~S} 2, \mathrm{~S} 3, \mathrm{~S} 4, \mathrm{~S} 5, \mathrm{~S} 6$ and $\mathrm{S} 7$ are allowed to make transitions to prison states because of their previously committed crimes. The primary data sources to estimate the prison transition probabilities were the published results from a study about engagement with criminal justice system among opioid dependent people in NSW (Degenhardt et al. (2013)).

The alleged individuals (based on crime committed rates) can be proved or pledged guilty. The weighted average prison terms in the local and district courts by categories of offences were used to assign length of stay to individuals who enter prison (BOCSAR Court Data Report, 2012). All transition probabilities of imprisonment from S1-S7 are dependent on age, gender, and state history.

Transitions from prison states to community states: Individuals can move to one of states in community on the completion of their stay in prison.

\section{Mortality}

The model considered variety of mortality rates based on the individual characteristics such as length of stay in the current state and history of previous state. The data for these mortality rates were derived from PHDAS, ATOS, and RCT sample. The specific rates (crude mortality rates (CMR) per 1000 person years (PY)) used in the model are illustrated in Table IV.

TABLE IV. MORTALITY RATES FOR EACH STATE

\begin{tabular}{llll} 
State: In & State: From & Time & CMR (/1000PY) \\
\hline S1 & Any & fixed & $5.3(5.0$ to 5.6) \\
S2 & Any & fixed & $5.3(5.0$ to 5.6) \\
S3 & S1, S4, S5, S7 & 1st week & $17.4(11.7-25.0)$ \\
& & 2nd week & $20.1(13.8-28.4)$ \\
& S8 & 1st 2 weeks & $59.5(41.3-83.6)$ \\
& & out of prison & \\
& S2, S6, S10 & Other time in S3 & $11.5(11.1-12.0)$ \\
S4 & anywhere & fixed & $6.0(5.76 .4)$ \\
S5 & anywhere & fixed & $6.0(5.76 .4)$ \\
S6 & S3, S4, S5, S7, S8 & 1st week & $39.5(31.9-48.8)$ \\
& S10 & 1st week & $10.9(4.0-23.8)$ \\
& S6 & 2nd week & $17.0(11.8-23.6)$ \\
& S6 & Other time in S6 & $5.6(5.2-5.9)$ \\
S7 & S3,S4, S5, S6 & fixed & $6.0(5.7-6.4)$ \\
S8 & anywhere & fixed & $2.7(2.0-3.7)$ \\
S9 & anywhere & fixed & $0.7(0.3$ to 1.2$)$ \\
\hline
\end{tabular}

\section{Estimating costs}

Treatment costs: The primary source for resource use information for treatment was extracted from individual care plans developed for the National Drug and Alcohol-Clinical Care and Prevention (DA-CCP). Care plans for opioid substitution, withdrawal, residential rehabilitation, and counselling for populations aged 18 to 64 were used. Information on staff type and time, pharmaceuticals, diagnostics, overhead and administrative allocations were obtained from respective care packages for each treatment. Once identified, resources were costed in 2012 AUD, sourced from NSW Wages and Salaries, Medical Benefit Schedule, Pharmaceutical Benefits Schedule (NSW Health 2015, PBS 2015, MBS (2015)). Costs were estimated for an episode, and then a cost per day was calculated for use in the model.
Criminal justice system costs: Unit costs were obtained from multiple sources and were adjusted to 2012 AUD as necessary. The average cost of a day in prison in NSW was sourced from the Report on Government Services as was the average cost per charge in the Magistrates Court (Productivity Commission 2015). Social costs of crime were obtained from an Australian report which included the intangible losses, property losses, and medical costs by type of offence (Russell et al. (2013)). The costs of policing were also estimated (Byrnes et al 2012), with annual non-capital expenditure on policing (Productivity Commission 2015).

Value of Statistical life year: According to Access Economics (2008) the mean of value of a life from these 17 studies was $\$ 5.7$ million (range \$0.9 to \$28.4 million 2006 AUD). After further analysis the recommendations from this report suggest using \$6.0 million 2006 AUD (range \$3.7 to $\$ 8.1$ million). After adjusting to 2012 AUD with the CPI, the value of a life was estimated to be $\$ 7.0$ million (range $\$ 5.87$ -\$8. 34 million). This value was annuitized over 80 years with a $3 \%$ discount rate. Then the total value over the remaining expected lifespan was calculated.

Other health care utilization costs: Estimates of other health care utilisation were estimated as daily costs. These included utilisation of inpatient, emergency department, outpatient services, general practitioners, specialists, and ambulances by model state were obtained (NHC 2015, DoH 2014, ASNSW 2015). These costs were then applied in the model as relevant.

\section{Benefits}

Individuals who are in states S1, S2, S3, S6 and S7 can be employed. The probability of employment increased if individuals maintained longer duration in abstinence and pharmacotherapy treatment. It was assumed that the longer duration of abstinence and in maintenance treatment increased participants probability of employment. Probabilities of employment were derived from ATOS, MIX, and NSW Labour Statistics 2012. If the participant is employed, the benefit was calculated as equal to days of employment times earnings per day; if the participant is unemployed, the benefit was equal to zero. The mean weekly earnings by gender and age from the Employee Earnings Statistics published by the Australian Bureau of Statistics was used to calculate the total earnings in a state.

\section{HIV and Hep-C prevalence among heroin users}

The Hep-C prevalence and incidence rates were estimated from the literature (Shand et al. 2014) and the resulting calculated indicated that there were 62,056 individuals that were Hep-C infected. Then this number were split by applying age and gender distribution. Further, different stages of Hep$\mathrm{C}$ infection was also considered. Another estimation indicated that there will be 670 to 840 new cases of Hep-C each year.

It is estimated that there are between 12,500 and 15,000 cases of HIV in NSW (NSW HIV Strategy 2012-2015). The number of cases attributable to IDU is approximately $2 \%$; this is based on data that the prevalence of HIV is 1-2\% among people attending NSPs (HIV Annual Surveillance Report, 2014). This equates to 300 existing cases of HIV in NSW 
that are the result of drug use. Further, 458 new cases of HIV in NSW in 2012, 18 of these cases were attributable to drug use (16 male; 2 female).

\section{MODEL VALIDATION AND RESULTS}

The proposed simulation model was written in Java using the Eclipse IDE. The computer program was written following modular approach (object orient programming) for model components. Several verification tests were defined for each of the modules to verify the intermediate simulation outputs. The logic for transition of individuals within the conceptual model was matched with the output from the simulation model. Additionally, we have randomly selected some individuals in the simulation model and traced their behavior and matched that against our conceptual model logic. We have verified individual transitions within the model. The transition summary from the model was compared with the expected transition summary which was derived after manually inputting the values into the transition functions.

In terms of validation of the simulation model, we have used face validation and cross-validation. In face validation, we have conducted review meetings with the advisory group consisting of experts from the illicit drug field. The individuals, discrete health states, transition probabilities, costs, mortality, infection rates, and other parameters were also developed in conjunction with domain experts along with making simplifying assumptions to create the conceptual model. We also performed cross-validation by running the baseline simulation model and comparing its output with the published literature.

Cross-validation to existing datasets and published literature: The datasets and published literature which were not used for model building were used for cross validation exercise. Data on the overall behavior of illicit drug users were used for model validation. Following are some of the model validation results:

1) We have compared the simulation results to expected total number of individuals in S6. Estimates are used from NOPSAD data for the OTP numbers in treatment (on census day). According to this dataset, there were 18,715 individuals in OST treatment in NSW on the census day in 2012. It is expected that this number will grow at about $3 \%$ overtime assuming it will follow the previous trend. We compared this number with the number of individuals in state S6 in various simulated years. The rate of increase in the heroin users in S6 (OST) from simulation model was $2.929 \%$ ( $1.03-3.69$ at $95 \% \mathrm{CI})$.

2) Larney \& Indig (2012) estimated that the proportion of opioid-dependent prisoners receiving OST treatment was $43 \%$. Based on the model the percentage of opioid-dependent prisoners receiving OST treatment in prison was 41.07 (95\% CI $40.48-41.65)$.

3) According to the published literature, $60 \%$ of community participants are in some type of treatment. From the simulation model, the proportion of dependent users in some type of treatment was $48.71 \%$ (47.4255.89 at $95 \% \mathrm{CI}$ ).

4) Mortality rate for opiate related deaths in NSW, according to Roxburgh and Burns (2012), was compared with the rate of drug related deaths in the proposed model. The drug related deaths in NSW stated by Roxburgh and Burns (2012) for 15 - 54 years old population was 198 (at 95\% CI 112 - 283) from 1999-2008. This means that the drug related mortality rate was $0.0029(=283 / 97,592)-0.00114$ $(=112 / 97,592)$ (at $95 \% \mathrm{CI})$. From the simulation model, the rate of drug related deaths (for 18 to 54 years old) was 0.00308 (0.002730 - 0.003446 at $95 \%$ $\mathrm{CI})$, which is consistent with the rates reported by Roxburgh and Burns (2012).

5) Abstinence rate for 11 year follow up for dependent heroin users from ATOS study (Teesson et al. presentation) was used for validation. It is stated in the study that percentage of heroin dependent population decreases from $97.6 \%$ in baseline year to $15.1 \%$ in 11th year ( $85 \%$ decrease approx.). Based on the simulation model, we observed $47 \%$ decrease in heroin dependent population after 11 years. Similarly, percentage of dependent population in current treatment has decreased by $74 \%$ (after 11 years of simulation) compared to $46 \%$ stated in the Teesson et al. presentation.

6) Mortality rate for opiate related deaths in NSW, according to Roxburgh and Burns (2012), was compared with the rate of drug related deaths in the proposed model. The drug related deaths in NSW stated by Roxburgh and Burns (2012) for 15 - 54 years old population was 198 (at 95\% CI 112-283) from 1999-2008. This means that the drug related mortality rate was $0.0029(=283 / 97,592)-0.00114$ $(=112 / 97,592) \quad$ (at $95 \% \mathrm{CI})$. From the simulation model, the rate of drug related deaths (for 18 to 54 years old) was 0.00308 (0.002730 - 0.003446 at $95 \%$ $\mathrm{CI})$, which is consistent with the rates reported by Roxburgh and Burns (2012).

7) Abstinence rate for 11 year follow up for dependent heroin users from ATOS study (Teesson et al. presentation) was used for validation. It is stated in the study that percentage of heroin dependent population decreases from $97.6 \%$ in baseline year to $15.1 \%$ in 11 th year ( $85 \%$ decrease approx.). Based on the simulation model, we observed $47 \%$ decrease in heroin dependent population after 11 years. Similarly, percentage of dependent population in current treatment has decreased by $74 \%$ (after 11 years of simulation) compared to $46 \%$ stated in the Teesson et al. presentation.

Above-mentioned results indicate that the model results are consistent with the published studies. After validation, the results of the model which has been run for 25 years is obtained. The initial population was evolved in time to simulate population aging, individual transitions, HIV and Hep-C infection, crime, employment, and mortality. The costs and benefits was calculated based on individual life events. The initial state summary obtained yearly for 25 years of simulation model is illustrated in Fig. 2. The number of individuals who are incarcerated every year (for 25 years of simulation) and the type of crime is presented in Fig. 3. Costs such as state costs, crime costs, value of life year costs, HIV \& Hep-C treatment costs, and family burden costs are presented in Fig. 4. The mortality, HIV cases, and individuals with over 60 years of age 


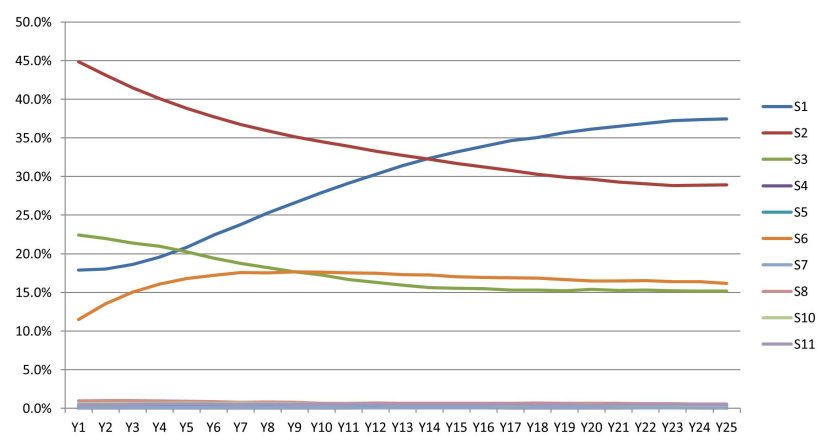

Fig. 2. State summary for 25 years of simulation

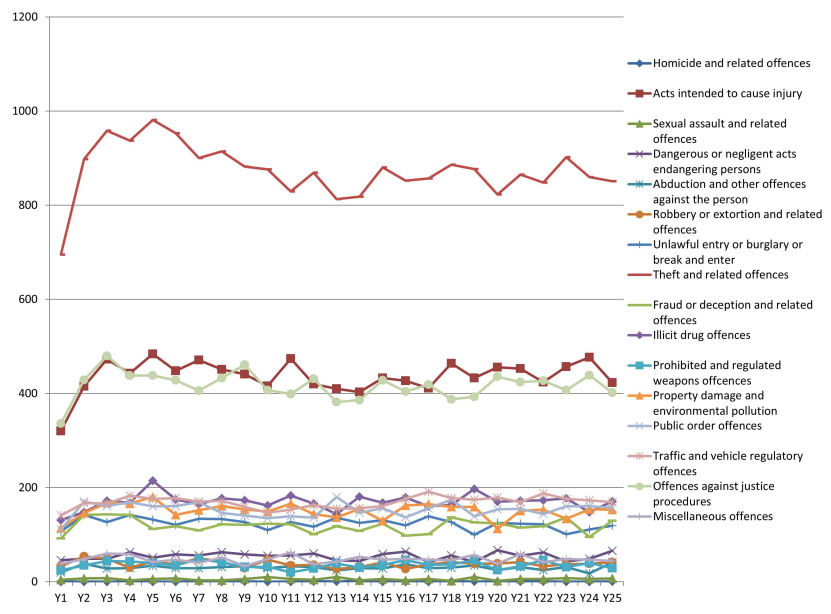

Fig. 3. Crime rates for 25 years of simulation

for 25 years of simulation is presented in Fig. 5. The current Heroin using population and their HepC status is presented in Fig. 6. The purpose of this paper was to showcase the model workings, initial validation and results. These results of the model can drive the discussion on government investments on drug treatment policy and decision making. It can also be used to simulate alternative policy scenarios, which is a topic of future research.

\section{Discussion AND CONCLUSION}

The ISM model developed in this paper has modelled range of treatment services in community and prison stages, and used variety of datasets from illicit drug user surveys and published literature. Traditionally, variety of economic evaluations based on simulation models in the field of illicit drug use had been developed. Nevertheless, most of these existing models were cohort-based models and lacks consideration for individual histories and attributes. The major weakness of cohort-based approach was that the future individual events did not depend on prior events. Similar simplifications can lead to misleading model based estimations. Individual sampling models based on microsimulation are starting to be used in health-care decision-making. These models have better ability to represent heterogeneity that is required in complex modelling scenarios

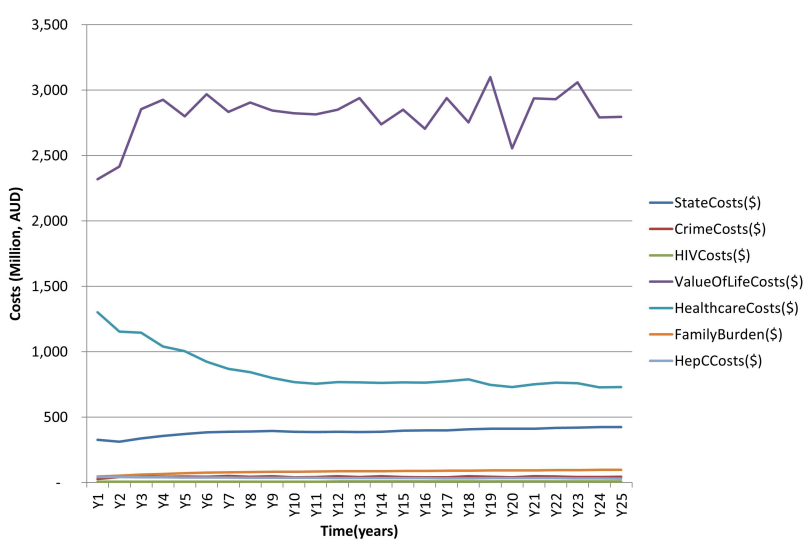

Fig. 4. Projected costs for 25 years of simulation

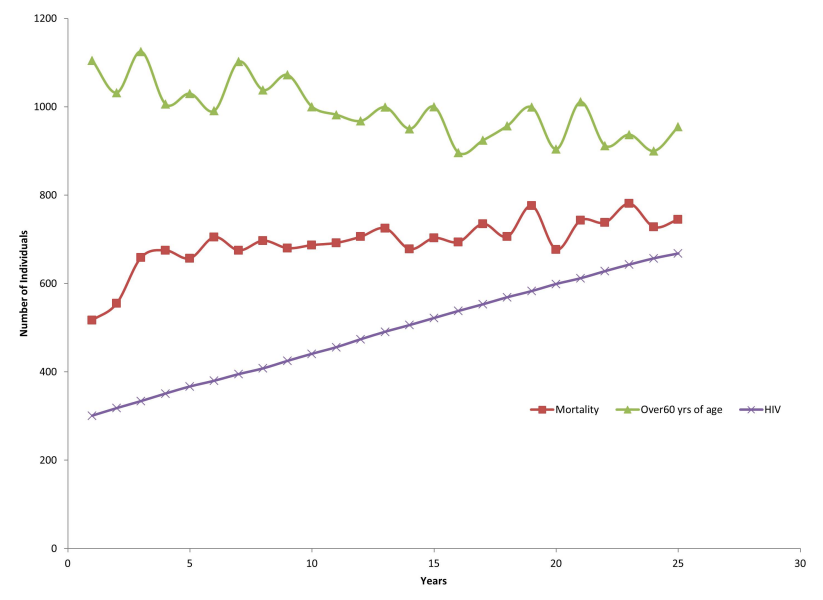

Fig. 5. Mortality, HIV status, and individuals over 60 yrs of age

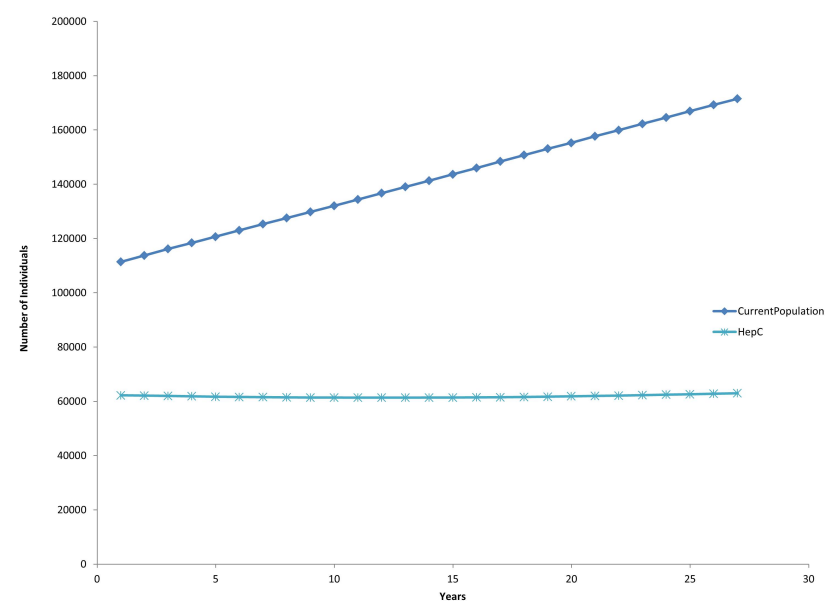

Fig. 6. Current Population of Heroin Users and their HepC status 
such as illicit drug use. Individuals in these models can take into account their histories to make decision on their next transition without creating large number of health states. Various features of proposed model for heroin use were validated against external datasets and published data in this field, which were not used as an input for model parameterisation. The model output seems coherent and does not significantly diverge from external datasets.

\section{ACKNOWLEDGMENT}

This work is supported by Project Grant (APP1042923) from National Medical and Health Research Council (NMHRC), Australia.

\section{REFERENCES}

World Bank. World Development Indicators 2012. Washington $D C$.

Schackman, B. R., Leff, J. A., Polsky, D., Moore, B. A., \& Fiellin, D. A. Cost-effectiveness of long-term outpatient buprenorphine-naloxone treatment for opioid dependence in primary care. Journal of General Internal Medicine, 27(6), 669-676, 2011.

Feldstein, M.S. Net Social Benefit Calculation and the Public Investment Decision Oxford Economic Papers, 16, 1964.

MBS 2015 Medicare Benefits Schedule (MBS) Accessed: 4/03/2015, http://www.health.gov.au/internet/ mbsonline/publishing.nsf

Degenhardt L, Gisev N, Trevena J, Larney S, Kimber J, Burns L, Shanahan M, Weatherburn D. Engagement with the criminal justice system among opioid-dependent people: a retrospective cohort study. Addiction. 2013 Dec;108(12):215265.

Burns L, Randall D, Hall WD, Law M, Butler T, Bell J, Degenhardt L. Opioid agonist pharmacotherapy in New South Wales from 1985 to 2006: patient characteristics and patterns and predictors of treatment retention. Addiction. 2009 Aug;104(8):1363-72.

Bell J, Mattick RP, Chan J, Hay A, Hall W. Methadone maintenance and drug related crime. Journal of Substance Abuse Treatment 9; 15-25, 1997.

Coffin PO, Sullivan SD. Cost-effectiveness of distributing naloxone to heroin users for lay overdose reversal. Ann Intern Med. 158(1):1-9, 2013.

Siebert U1, Alagoz O, Bayoumi AM, Jahn B, Owens DK, Cohen DJ, Kuntz KM. State-transition modeling: A report of the ISPOR-SMDM modeling good research practices task force-3. Value in Health, 15(6), 812-20, 2012.

Hser YI, Huang D, Chou CP, Anglin MD. Trajectories of heroin addiction: growth mixture modeling results based on a 33-year follow-up study. Eval Rev. 31(6):548-63, 2007.

Nosyk, B., Anglin, M.D., Brecht, M.L., Lima, V.D., Hser, Y.I. Characterizing durations of heroin abstinence in the California Civil Addict Program: results from a 33-year observational cohort study. Am. J. Epidemiol., 177: 675682, 2013.

Shah, N.G., Galai, N.G., Celentano, D.D., Vlahov, D. , Strathdee, S.A. Longitudinal predictors of injection cessation and subsequent relapse among a cohort of injection drug users in Baltimore, MD, 19882000. Drug Alcohol Depend., 83: 147156, 2006.
Termorshuizen F., Krol A., Prins M., Van Ameijden E. J. C. Long-term outcome of chronic drug use the Amsterdam cohort study among drug users. Am J Epidemiol 161: 271279, 2005.

Simpson, D.D. \& Marsh, K.L. Relapse and recovery among opiate addicts 12 years after treatment. In Tims, F.M. and Leukefeld, C.G. (Eds) Relapse and Recovery in Drug Abuse. NIDA Research Monograph 72, 1986.

Larney S \& Indig D. Trends in illicit drug use in Australian correctional centres. Annual meeting of the college of problems on drug dependence. California: Palm Springs, 2012.

Grnbladh, L., Gunne, L. Methadone-assisted rehabilitation of Swedish heroin addicts. Drug and Alcohol Dependence, Volume 24(1):3137, 1989.

Hser Y I, Evans E, Huang D, Anglin D M. Relationship between drug treatment services, retention, and outcomes. Psychiatr Serv.;55(7):767-74.

Zhang, Zhiwei, Friedmann, Peter D., Gerstein, Dean R. Does retention matter? Treatment duration and improvement in drug use. Addiction, 98(5): 673-684, 2003.

Zucchelli, E., Jones, AM and Rice, N. The evaluation of health policies through dynamic microsimulation methods. International Journal of Microsimulation, 5(1), 2-20.

Russell G Smith, Penny Jorna, Josh Sweeney,, Georgina Fuller. Counting the costs of crime in Australia: A 2011 estimate. AIC Reports Research and Public Policy Series 129, ISBN 9781922009708 ISSN 1836-2079, 2013. 